\title{
METRÓPOLE, COLÔNIA E SUAS RELAÇÕES EXPLOSIVAS: DA REVOLUÇÃO DOS CRAVOS EM PORTUGAL À INDEPENDÊNCIA DE ANGOLA EM ZERO HORA E CORREIO DO POVO
}

\section{METROPOLIS, COLONY AND EXPLOSIVE RELATIONS: CARNATION'S REVOLUTION IN PORTUGAL AND ANGOLA'S INDEPENDENCE IN ZERO HORA AND CORREIO DO POVO}

\author{
Mauro Luiz. Barbosa Marques ${ }^{1}$
}

\begin{abstract}
Resumo: Este artigo analisa a conjuntura do pós Segunda Guerra e todo contexto que relacionou a Revolução Portuguesa de 1974 com a independência de Angola no ano seguinte. Este cenário tornou os acontecimentos metropolitanos intrinsecamente vinculados à conjuntura colonial e à guerra ali desenvolvida. Para isso, ao lado da bibliografia sobre o tema, serão utilizados e comparados os conteúdos de Zero Hora e Correio do Povo, principais jornais do Rio Grande do Sul (Brasil) na época, os quais cobriram com intensidade estes eventos.
\end{abstract}

Palavras-chave: Imprensa e História. Independência de Angola. Revolução Portuguesa. Independências africanas.

\begin{abstract}
This Article analyze the conjuncture after Word War II and all context between Portuguese Revolution in 1974 and Angola's independence in the following year. This scenario linked the metropolitan events and the colonial conjuncture with the war developed there. For this goal, will be used bibliography about it and the content in Zero Hora and Correio do Povo, main newspapers at Rio Grande do Sul, Brazil, in that moment, when these periodic followed these events with intensity.
\end{abstract}

Keywords: Press and History. Angola’s Independence. Portuguese Revolution. African’s Independence.

\section{Introdução}

O contexto político internacional após a Segunda Guerra Mundial incidiu fortemente nas relações colonialistas na África e em outras partes do globo, especialmente a partir do momento em que as potências colonialistas europeias saíram fortemente abaladas deste conflito e por conseqüência, debilitadas no concerto do poder internacional.

Até o início do século XX, parecia impossível imaginar uma decadência dos países europeus. Autodenominados de potências, ampliaram sua influência cultural e política no mundo especialmente com o colonialismo. Na Conferência de Berlim², em 1885, bastante unidos, tentaram dividir o mapa africano entre as sete potências que ali detinham algum tipo

\footnotetext{
${ }^{1}$ Mestre em História pela Universidade Federal do Rio Grande do Sul (UFRGS) e professor da rede pública na cidade de São Leopoldo. Este artigo é parte (adaptada e ampliada) da dissertação "Entre ferro e fogo: os noticiários da imprensa sul rio-grandense sobre o governo Agostinbo Neto em Angola (1975 - 1979)", que analisou o conteúdo da imprensa do Rio Grande do Sul quando cobriu a independência angolana e a consolidação deste Estado Nacional na década de 1970.

2 Conferência realizada pelas chamadas potências européias que acabou dividindo o mapa africano entre portugueses, espanhóis, belgas, ingleses, franceses, italianos e alemães criando diversas fronteiras que visavam à ocupação militar, política e econômica destes espaços (BRUNSCHWIG: 2004, p. 37 a 41).
} 
de ocupação ou 'mérito' imperialista. Foi a última centelha da energia expansionista (em que pese muito importante) dos europeus.

Mesmo as nações vencedoras na Segunda Guerra, foram fortemente abaladas e por conseqüência, o colonialismo por elas levado a cabo se esfumaçou. Foi o momento no qual surgiu os EUA como grande potência por ter saído da "II Guerra com extraordinário poderio econômico e político (...). Assumiram a posição de liderança do mundo capitalista" (LOPEZ: 1987, p. 120). Por outro lado, a URSS, em que pese ter enfrentado devastação devido à ocupação de seu território, viu seu poderio bélico se consolidar ao derrotar os alemães e ampliar seu leque de influência internacional a partir dos acordos de Yalta e Potsdam em 1945.

Estas potências surgidas após 1945 (EUA e URSS) polarizaram as lutas políticas no planeta entre as décadas de 1950 e 1980. Este fator foi importante e ativo nas independências africanas. ${ }^{3}$ EUA e URSS desenvolveram diversos confrontos indiretos em várias partes do globo, destacando-se os processos de descolonização africana, em especial os episódios das independências das possessões portuguesas.

Em Angola, caso estudado neste artigo, ocorreu um trauma violento, desde os anos 1960 e o início do processo de luta nacional pela independência. Ali, ao menos três exércitos guerrilheiros se enfrentaram armados pelos dois blocos da Guerra-Fria. Esta realidade angolana foi parte de todo processo de reação organizada africana, ao mesmo tempo em que os europeus, imersos nas tarefas de reconstrução nacional reduziam sua presença real nas áreas coloniais.

Segundo Iliffe, a ação africana se constituiu em uma "energia libertadora que destruiu o domínio europeu e o crescimento sem precedentes da população, de pouco mais de 200 milhões em 1950 para 600 milhões em 1990” (1995, p. 315).

Abriu-se um período intenso de rupturas coloniais a partir de 1960, quando a África reagiu, 60 anos depois da colcha de retalhos fabricada na Conferência de Berlim. Segundo Ferro, os lutadores pela independência na África perceberam que "os brancos e seus Estados podiam ser derrotados, total e vergonhosamente, e que as velhas potências se encontravam fracas demais (1996, p. 214).

Os EUA, ausente nas possessões africanas, tinham uma posição clara a respeito da autodeterminação dos povos a partir das ideias da Carta do Atlântico (14 de agosto de 1941)

3 Tanto EUA como a URSS apoiaram militar e politicamente os movimentos de libertação nacional, especialmente em Angola, mais um dos inúmeros panos de fundo na disputa de hegemonia entre ambos. O sistema de acordo conflitivo conhecido como Guerra Fria marcou praticamente todas as disputas políticas no mundo entre os anos 1945 e 1991. Nesse período, houve uma divisão de esferas de influências entre os dois blocos os quais apresentavam entre si, entre outras coisas, importantes diferenças econômicas e sociais na organização de seus países, a partir da dicotomia socialismo versus capitalismo (Ver HOBSBAWN, 2004). 
assinada também pelos ingleses ${ }^{4}$. Por sua vez, a URSS se destacou como apoiadora dos movimentos nacionalistas de libertação, na oposição ao que denominava imperialismo capitalista.

A ONU, que estava nascendo na medida da derrota alemã, se dispunha a pôr em prática um sistema internacional garantidor dos direitos humanos e da paz a partir de "meios pacíficos". Esta entidade teve tradição no reconhecimento de novos Estados oriundos de rupturas coloniais.

As rupturas coloniais que não tardaram, aconteceram de duas formas básicas: a partir de lutas populares anticolonialistas ou acordos que evitavam os traumas da violência e garantiram algum tipo de vínculo com a ex-metrópole, exemplo muito visto nas colônias britânicas.

Conforme Chaliand: “A África ao sul do Saara, no essencial, exceção feita às colônias portuguesas (...), acede à independência por volta de 1960 sem disparar um tiro sequer. (...), pode-se legitimamente empregar o termo descolonização" (1982, p. 25).

Dada a vinculação do colonialismo com o modelo capitalista de economia, os partidos e grupos com referência no socialismo tomaram o poder em várias ex-colônias africanas:

Em várias ex-colônias, os comunistas tomaram o poder, dada a sua identificação com o anticapitalismo e, portanto, com o antiimperialismo, particularmente em países que se formaram a partir da vitória de uma insurreição popular organizada e mantida tenazmente à base da guerrilha, como na Indochina, em Moçambique e em Angola (LOPEZ: 1987, p. 127).

A formação da Organização da Unidade Africana ${ }^{5}$ e as lutas internas desta entidade também foram influenciadas pelas posições e disputas entre socialistas e capitalistas, algo natural num mundo politicamente bipolarizado, com pouco espaço para uma espécie de terceira vertente.

As potências também se tornaram espécie de modelo para os Estados recém libertados, sendo para estes uma referência em termos econômicos, políticos e administrativos e "não os governos minimalistas das sociedades agrícolas mas os planos de desenvolvimento e os mecanismos de controlo burocrático do mundo industrializado (em especial do socialista)" (ILIFFE: 1995, p. 326).

\footnotetext{
${ }^{4}$ A Carta do Atlântico destacava os seguintes princípios: 1. A renúncia a qualquer aquisição de território sem o prévio conhecimento das suas respectivas populações. 2. O direito de autodeterminação dos povos. 3. Acesso de todos os Estados ao comércio internacional. 4. Liberdade dos mares (LINHARES, 1981, p.15).

${ }^{5}$ Em maio de 1963 foi fundada em Adis Abeba, a OUA que pretendia dotar a África de uma poderosa voz independente nos assuntos internacionais. 30 nações africanas fundaram a OUA (READER: 2002, p. 652).
} 


\section{O contexto português}

Portugal participou ativamente da Conferência de Berlim. A partir de então, garantiu a posse de Moçambique, Angola e Guiné, somando-se as ilhas de Cabo Verde e S. Tomé e Príncipe. O colonialismo português sempre teve relação estreita com a conjuntura da metrópole portuguesa.

A partir de 1926, Portugal entrou num regime militar ditatorial fundado por um golpe liderado pelo General Gomes da Costa que durou, com suas variações, até a Revolução dos Cravos em 1974. Gradualmente, Antonio de Oliveira Salazar dominou o governo e impôs seu sistema político simpático ao fascismo, embora tenha se mantido neutro durante a Segunda Guerra Mundial.

Em 1933 se inaugurou a fase chamada de Estado Novo, regime de forte censura e onde colocava os interesses individuais abaixo dos interesses da nação. Em relação às colônias, a filosofia salazarista, através do Ato Colonial de 1930 afirmava que

após quase uma década de controvérsia e de luta por modelos alternativos traçara rumos de uma política colonial baseada no nacionalismo, na promoção da 'mística imperial', na centralização de poderes e no equilíbrio financeiro, com inteira subordinação dos interesses das colônias aos da metrópole (SILVA: 1997, p. 22).

A citada mística imperial, aliás, era o pouco que sobrava do antigo império mercantilista. Portugal se colocava como um país retrógrado, entre os mais pobres da Europa, com orientação fascista e dependente do capital externo inglês. Ao final da Segunda Guerra, Salazar previu dificuldades para a manutenção das possessões coloniais e do próprio regime interno. Por isso, houve mudanças no estatuto colonial visando manter o patrimônio atlântico como pilar da política externa portuguesa.

Assim, em 1951, as colônias se tornaram Províncias Ultramarinas, que para os interesses salazaristas representou a afirmação de um Portugal igualitarista, um país multicontinental e fraterno. Com esta nova denominação Portugal chegou a afirmar perante a ONU em 1955 “não administrar territórios não autônomos” (SILVA, 1997, p. 33).

Independente da vontade portuguesa, os ventos internacionais sopravam no sentido da descolonização e o velho Império sofreu pressão internacional da ONU, das populações coloniais com suas organizações armadas e mesmo de parte da população metropolitana. Assim, o ano de 1956 foi marcado pela forte presença dos movimentos de libertação colonial que tem este ano como sua fundação ou consolidação. 
Entre 1961 e 1963 as guerras de libertação iniciariam em várias frentes, especialmente Guiné e Angola. A reação portuguesa foi dura, aos moldes do regime salazarista. Centenas de milhares de soldados portugueses, num país com menos de 10 milhões de habitantes, foram mobilizados para as guerras coloniais, nas quais mais de 10 mil foram mortos ou feridos. Entre $40 \%$ e $50 \%$ do orçamento português era despendido para manutenção das colônias e repressão as movimentos de libertação.

Salazar teve um acidente doméstico em 1968 (morreu em 1970) e Marcelo Caetano o substituiu na chefia do governo. Era a garantia que sua concepção política sobrevivia a sua morte. Marcelo mudou um pouco a lógica política em relação às colônias. Enquanto Salazar trabalhou a idéia de "defesa das colônias e da unidade portuguesa", Caetano priorizou a defesa da "população branca ali instalada (nas colônias)", conferindo grau maior de autonomia, sem abrir mão da unidade portuguesa, dentro e fora da Europa (SILVA: 1997, p. 87).

Portugal foi o último bastião de um colonialismo conservador de inspiração fascista e baseado na superioridade racial (LINHARES: 1981, p. 96). Este sistema, baseado num reacionário colonialismo motivou vários movimentos representativos da organização desta luta e muitos quadros políticos opositores ao Estado Novo se formaram nas fileiras do MUD (Movimento de Unidade Democrática), fundado em Portugal em 1945.

Era uma articulação antifascista democratizante, onde futuros quadros da resistência africana redescobriram a solidariedade e a sua cultura originais. Dali, alguns contribuíram na construção de organizações para a luta anticolonial em Guiné Bissau, Moçambique e Angola. Com fortes coincidências programáticas adotaram a luta armada e a guerrilha organizada como método de luta.

Em Angola, Agostinho Neto formou o MPLA (Movimento Popular para Libertação de Angola) a partir da clandestinidade e acabou chegando à presidência após a independência. Diferentemente de Moçambique e Guiné, em Angola houve grupos guerrilheiros rivais além do MPLA: a FNLA e a UNITA .

Merece destaque no marco da unidade africana anticolonialista a formação do MAC (Movimento Anticolonialista para a Libertação das Colônias Portuguesas), que integrou nativos de todas as colônias portuguesas a partir de 1957.

Fundado em Paris, reforçou a luta contra o colonialismo desde fora da África e inseriu-se numa época “em que, após a Conferência de Bandung, vários congressos de estudantes, escritores e artistas negros, partidos e movimentos políticos agitaram a África de uma ponta a ponta" (SILVA, 1997, p. 40). 
As organizações anticolonialistas, já aparecem nos jornais gaúchos. Em artigo no Correio do Povo (CP), Joseph Dynan, da AP confirmava que os

problemas africanos de Portugal começaram em 1961, quando ali penetraram grupos guerrilheiros procedentes da República do Congo para atacar colonizadores portugueses. Desde então, a campanha da África tem se intensificado a tal ponto, que Portugal introduziu em seu território cerca de 142.000 homens. ("Os problemas de Portugal na África" - 19/03/74, p. 2).

Em Zero Hora $(\mathrm{ZH})$, os conflitos entre os guerrilheiros e o exército português foram destacados em manchetes como "Mais de 100 portugueses mortos pelos guerrilheiros da Guiné”, (20/2/74, p. 11); “Combate em Moçambique destrói aldeia e mata 17” (11/1/74, p. 14) e "Portugueses encurralados na África", onde se leu: "FRELIMO (...) lançou uma grande ofensiva para expulsar da África um dos últimos países colonialistas ao velho estilo" (3/1/74, p. 14).

Por vezes originadas no exterior, com seus líderes tendo formação acadêmica nas metrópoles, estas organizações de luta anticolonial teceram redes importantes com as massas colonizadas nas possessões portuguesas. Nas lutas, não esqueceram em sua prática política a importância da luta continental e mesmo mundial contra o colonialismo e outras formas de imperialismo.

\section{As lutas anticoloniais em $\mathrm{ZH}$ e $\mathrm{CP}$}

Entre os anos 1974 e 1975, o tema da libertação das colônias portuguesas e o contexto da metrópole esteve em dezenas de edições em ZH e CP. Estes periódicos aproveitaram a liberdade que as temáticas internacionais gozavam, apesar da censura geral na qual os periódicos estavam imersos no período militar brasileiro.

Também, o regime militar era simpático em relação às independências africanas, especialmente no governo Geisel que buscava ampliar o quadro de relações internacionais do Brasil num cenário de crise internacional. O sr. Olyr Zavaschi nos lembra que

$$
\begin{aligned}
& \text { certamente não houve restrições a que os jornais publicassem os fatos de acordo com } \\
& \text { o que as agências de noticias transmitiam. Havia, se bem me lembro, a impressão de } \\
& \text { que o governo militar era simpático à libertação de Angola, Moçambique e Guiné, } \\
& \text { impressão que se consolidaria com o reconhecimento de Angola pelo governo } \\
& \text { brasileiro. O Brasil foi a primeira nação a fazer isso. }
\end{aligned}
$$

O Brasil rapidamente reconheceu todas as independências das possessões portuguesas, além do governo português pós 25 de abril. Ainda deu asilo político a Américo Thomas, Marcelo Caetano e Spínola, centrais personagens na trama portuguesa entre 1974 e 1975. O sr. Jurandir Soares complementa que 
na Editoria Internacional não houve interferência e, embora o governo militar brasileiro não compactuasse com o que acontecia em Portugal, não tivemos censura quanto às notícias sobre a Revolução dos Cravos e sua extensão. Eu tinha plena autonomia para escrever críticas contundentes que eu fazia, por exemplo, às ditaduras de Pinochet, no Chile, ou de Franco, na Espanha. Parece que a filosofia era que as outras ditaduras podiam ser criticadas, menos a brasileira. ${ }^{6}$

A partir desta certa liberdade editorial, ZH e CP investiram na cobertura de Portugal e suas possessões com articulistas, enviados e redatores sempre atualizados sobre a conjuntura da descolonização. ZH contou com Newton Carlos em sua coluna de política internacional. Em janeiro de 1974, este já previa o "Fim do Colonialismo" (29/1/74, p. 12) em coluna dedicada à crise portuguesa onde caracterizou o regime salazarista dirigido então por Marcelo Caetano como "estagnado e imobilista".

Cerca de um mês antes da Revolução dos Cravos, Newton Carlos publicou outro artigo no qual relatou os problemas de fronteira entre Angola e Moçambique de um lado e os regimes de minoria branca da Rodésia e África do Sul de outro, estes preocupados com os movimentos de libertação coordenados por grupos negros e de inspiração socialista.

A partir disso, comparou o contexto português como um Vietnã Africano, metáfora aludindo à derrota estadunidense na Ásia naquele período, onde já anunciava que a crise portuguesa "não deve ser acompanhada, portanto, só a partir de acontecimentos em Portugal" (ZH: 19/3/74, p. 12). O recurso gráfico das expressões carregadas de valor como Vietnã Africano é uma forma de potencializar o texto e um recurso claro do "locutor frente ao que está sendo referido e contextualizado. São adjetivos no sentido de atribuir um valor a coisas ou pessoas, refletindo com isso concepções de mundo, de valor cultural ou ideológico" (RECH \& FELTES: 2005, p. 280).

Ainda no mês de março, ZH alertou em artigo de página inteira, intitulado "Futuro de Portugal em Debate" que a partir da crise do petróleo, Portugal estava encurralada "numa Europa que se projetou decididamente a favor dos árabes e, por extensão, dos africanos. Em troca do apoio à causa árabe, os africanos exigiram dos árabes apoio à causa anticolonialista" (17/3/74, p. 16).

CP, por sua vez, incluiu artigos oriundos de agências da UPI/AP. Em artigo onde destacou "Os Problemas de Portugal na África”, já apontou como solução para os problemas

\footnotetext{
${ }^{6} \mathrm{O}$ sr. Olyr Zavaschi nos elucidou importantes aspectos do cotidiano editorial de ZH nos anos $1970 \mathrm{em}$ gentil entrevista. Atualmente é editorialista da página Almanaque Gaúcho em ZH, sendo na década de 1970 editor do noticiário internacional deste jornal. O sr. Jurandir Soares era Analista de Assuntos Internacionais do Jornal Folha da Tarde nos anos 1970 (também entrevistado). Antes da venda desta Rádio ao Grupo RECORD, apresentava o Programa BOM DIA na Rádio Guaíba. Ainda hoje pertence aos quadros profissionais da emissora (nota do autor).
} 
portugueses as teses do General Antonio Spínola, naquela altura já lembrado pelo seu livro "Portugal e o Futuro". A matéria destacou: "o livro provocou um surto de rebelião por parte de jovens oficiais de Infantaria, que, ao que parece, estão convencidos de que Portugal necessita de uma solução política para seus problemas coloniais" (19/3/74, p. 2).

A insistência em ZH e CP da "solução do problema" lembra o conceito da pesquisadora Maria Aparecida Aquino (1999) acerca do "retorno à ordem pública". Ao mesmo tempo, CP divulgou em alguns momentos a visão dos guerrilheiros (o mesmo não ocorreu em ZH neste período).

Para GOMES (artigo virtual), a versão dos guerrilheiros cabe dentro do jornalismo, considerando que este não está "isento das falas da rebeldia, vozes de revoltas, conflitos, contradições e paradoxos". Estas vozes se tornam importantes até para garantir o discurso de imparcialidade que a imprensa costuma colocar para si.

Levando em conta todos estes aspectos, o conteúdo das notícias, das manchetes e dos editoriais esteve presente na abordagem da Revolução dos Cravos - e seus momentos anteriores - e na cobertura da independência angolana.

\section{A Revolução dos Cravos: a rebeldia chega à Metrópole}

A decadência econômica de Portugal, seu isolamento político, o desgaste com a guerra colonial e o acirramento da luta de classes provocaram forte descontentamento no interior das Forças Armadas e em boa parte da sociedade portuguesa. A situação interna portuguesa era repleta de paradoxos: chegava a ocorrer um colonialismo ao avesso lembrado por Perry Anderson, pois

\footnotetext{
a clássica absorção colonialista de matérias-primas para reexportação não ocorre. A balança é exatamente inversa: exportação quase total de matérias-primas (cortiça, vinho, etc., envolvendo um mínimo de intervenção tecnológica) e importação de manufaturados. O padrão é assim o verdadeiro reverso de uma economia imperialista (1966, p. 7).
}

Portugal, em quase todos os aspectos, estava na retaguarda européia: mais de $40 \%$ de analfabetismo, maior taxa de mortalidade infantil, graves problemas sanitários e de saúde pública, constante emigração que fez a população portuguesa reduzir nos anos 1970 e um regime político antiquado sustentado em uma aliança societal entre clero, latifúndio e 
ideólogos fascistas. Para Anderson, Portugal vivia um regime fascista, com a ideologia corporativista $^{7}$ definida desde os tempos de Salazar.

O antigo Império português, do qual restava com otimismo apenas sua mística, se encontra nos anos 1970 totalmente subalterno ao capital monopolista em suas várias formas, "como ditadura terrorista aberta dos elementos mais reacionários e mais imperialistas do capital financeiro" (NETTO: 1986, p. 20).

$\mathrm{Na}$ prática, onze grupos monopolistas portugueses controlavam os negócios, em acordo com o latifúndio e o capital estrangeiro. Ministros, altos escalões e funcionários do regime salazarista compunham parte dos conselhos e das administrações em muitos destes grupos. ${ }^{8}$

Segundo Anderson, a entrada de capital britânico em Portugal era "mais profunda do que em qualquer outro país europeu" (1966, p. 10). Este aspecto também justifica o vigor da luta portuguesa, cada vez alienando mais sua soberania para defender na África os investimentos privados internacionais.

As transnacionais dominavam total ou parcialmente áreas da economia como telefonia, comunicações internacionais, comércio de óleos minerais, fabricações de veículos e diversos produtos. Para Netto, era o jardim da Europa "para uma restrita oligarquia de grandes capitalistas e latifundiários" (1986, p 28).

Foi este contexto que levou à oposição antifascista, em suas mais variadas feições, levar a maioria do povo julgar este velho regime em ações radicalizadas nas ruas, pois enquanto boa parte da África se tornava independente, Portugal insistia em seu modelo de colonialismo. Pimenta (2008, p. 65) relata sobre as intenções de Marcelo Caetano ${ }^{9}$, chefe do governo português nas vésperas da Revolução de 25 de abril:

Marcelo Caetano afirmou explicitamente que a sua política de reforma do colonialismo português passava pela "autonomia progressiva do governo" das colônias, pela participação crescente das populações coloniais nas estruturas políticas e administrativas dos respectivos Estados coloniais e pela atribuição do "governo próprio" às colônias africanas.

\footnotetext{
7 O corporativismo visava colocar o Estado como mediador de interesses entre grupos conflituosos, especialmente os empregadores e seus trabalhadores. Para garantir esta mediação se impunha um regime unipartidário (União Nacional era o único partido) de violência e coerção (1966, p. 11).

${ }^{8}$ No campo, é demonstrada a concentração fundiária ao se notar que 500 grandes proprietários detinham mais terras que os 500 mil proprietários menores (NETTO: 1986, p. 25).

9 António de Oliveira Salazar (1889 - 1970) exerceu o poder político em Portugal entre 1932 e 1968, quando ajudou a instituir o regime chamado Estado Novo, (1933 - 1974) de inspiração fascista. Afastado por motivo de saúde do poder, foi assim substituído por Marcelo Caetano (1906 - 1980) na chefia do governo português, até a derrubada deste e do regime apelidado de "salazarista", pela Revolução dos Cravos em abril de 1974 (MAXWELL: 2006, p. 42 e seq.).
} 
As opções portuguesas eram opostas às tendências daquele momento e por este motivo, Marcelo Caetano caiu junto com o seu regime perante lutas populares, operárias e das próprias Forças Armadas que acabaram contribuindo para o fim do Império português africano e sua guerra insistente nas colônias, as quais reduziam as chances de elevar o padrão de vida português aos níveis europeus.

Portugal não podia continuar a comprometer a economia, estrangulada para "sustentar um exército de 170 mil homens" e os imensos esforços e guerra colonial (MAXWELL: 2006, p. 57). Esta conjuntura levou a que setores importantes da média oficialidade militar portuguesa organizassem um levante armado, com apoio popular significativo, que derrubou Caetano e encerrou o período do Estado Novo na história política de Portugal. Era a Revolução dos Cravos de 25 de abril de $1974 .^{10}$

\section{Antônio de Spínola, MFA e a queda do regime português}

A partir dos anos 1960, o regime salazarista experimentou seu declínio irreversível. A guerra colonial na África, além do arrocho às finanças portuguesas, colocou parte de sua juventude alistada em missões com risco de morte ou mutilamento em um conflito sem sentido longe de casa.

Além disso, existiu uma curiosa relação entre Forças Armadas e guerrilhas africanas, pois muitos oficiais tiveram contatos com o mundo das idéias marxistas (que os grupos guerrilheiros defendiam) e visões de Mao, Che Guevara, Samora Machel, entre outros (SECCO: 2004, p. 104).

O descontentamento das condições insalubres da guerra, somado aos revezes do conflito e ataques a moral das Forças Armadas criaram uma compreensão entre oficiais, soldados e parte da população metropolitana que era necessária uma saída política e não militar para o conflito. Eram os dias da derrota estadunidense no Vietnã e neste contexto destacou-se Antônio de Spínola.

Spínola fora governador da Guiné nomeado em 1968 pelo regime salazarista. Era um dos mais altos e condecorados militares no prestígio das Forças Armadas portuguesas. Para Silva, Spínola já naquela altura priorizava a saída política para o conflito nas colônias (1997, p. 89).

\footnotetext{
10 “A Revolução na metrópole colonialista e as crises que levaram Portugal decisivamente para esquerda também deram um impulso à independência da África portuguesa. Surgiram como uma série de lutas, às vezes demoradas, nas quais tensões políticas em Portugal, acontecimentos na África e pressões externas combinaram-se, gerando graves confrontos" (MAXWELL: 2006, p. 117).
} 
Seu livro, "Portugal e o Futuro", bastante destacado no contexto imediatamente anterior à Revolução dos Cravos não defendeu a idéia da independência total das colônias portuguesas africanas. Formulou que "a vitória exclusivamente militar é inviável” e apontou três alternativas:

ou se envereda pelo caminho das concessões crescentes em cadeia, caminho que conduz a um ponto de rotura no limite das possibilidades de concessão; ou se entra no campo da repressão totalitária, o que acelera a violência; ou se acerta o caminho da liberalização, que também tem o seu reverso, mas que apesar de tudo cremos ser a solução, (...), na disciplina e sob o signo de uma firme autoridade então fortalecida pela via da legitimidade (SPÍNOLA: 1974, p. 47).

O caminho da "liberalização" citado pelo autor se conseguiria a partir do "reconhecimento do direito dos povos à autodeterminação" a que acrescentou a necessidade da unidade e da expressão de instituições africanas bem como do princípio de "consulta popular" via referendo de toda Nação portuguesa. Esta autodeterminação não levava necessariamente "à amputação de membros. Só nessas bases, despidas de contradições, será possível construir uma sólida Comunidade Lusíada” (1974, p. 122).

Esta "Comunidade Lusíada", que Spínola esperava incluir o Brasil, além de Portugal e os africanos, era uma espécie de retomada, pois "Portugal foi o primeiro Império colonial, hoje é o último, e talvez seja o primeiro de uma nova era" (1974, p. 96).

Por fim, a teoria spinolista objetivamente rejeitou a possibilidade da independência pura e simples das colônias, pois isso iria "afetar nossa sobrevivência como nação livre; por não podermos abandonar os que no Ultramar construíram as suas vidas” (1974, p. 55).

Apesar de seus limites, o livro de Spíno1a foi campeão de vendas em Portugal e teve grande repercussão na imprensa do Rio Grande do Sul. Em ZH, as teses de Spínola foram amplamente divulgadas em artigo e consideradas como "estopim da crise que agita os meios políticos e militares portugueses" (17/3/74, p. 16). Já em CP, a simpatia é mais clara a respeito das opiniões spinolistas, tidas simplesmente como "solução", palavra destacada em subtítulo $(19 / 3 / 74$, p. 2).

Independente da caracterização sobre as afirmativas de Spínola, seu livro acabou proibido e o governo português prometeu "processo de demissão para quem publicar livro de Spínola" (CP, 21/3/74, p. 3). Antes disso, Caetano havia afastado Spínola e o General Costa Gomes de suas funções, como retaliação e demonstração que manteria sua política africana. Tudo isso acabou sendo um tiro pela culatra e a gota d'água para o fim do velho regime fascista português. 
Junto aos posicionamentos de Spinola, logo se formou o $M F A$, Movimento das Forças Armadas, surgiu em Portugal a partir do movimento dos capitães no ano de 1973. Era um grupo heterogêneo que se equilibrava em uma plataforma política de ação que incluía a saída política para o impasse da guerra colonial.

Conforme Secco, a partir de uma reunião em dezembro de 1973, se traçou a necessidade de "substituir o governo de Marcelo Caetano, por meio de um golpe que restituísse às Forças Armadas seu prestígio. Foi então institucionalizada a Comissão Coordenadora do Programa (CCP), responsável pela direção do MFA” (2004, p. 108).

A idéia da busca do prestígio perdido, mostra a situação das Forças Armadas, que além de amargar soldos rebaixados sofria uma precarização constante em seus quadros, com novas formas de ingresso no quadro militar que ofendia os velhos oficiais de carreira. Ressalte-se que nessa altura, a oposição civil praticamente nada sabia dos movimentos conspirativos do MFA.

$\mathrm{O}$ jornal ZH localizou corretamente a conjuntura afirmando que a "política portuguesa nas colônias da África, além de estarem levando Portugal à bancarrota econômica e à derrota militar, provoca agora uma grande divisão nas Forças Armadas" (13/3/74, p. 14). $\mathrm{Na}$ mesma matéria, ZH dividiu as forças Armadas entre os setores "duros", seguidores do regime português e os "rebeldes ultras", identificados entre a jovem oficialidade. Segundo ZH, os jovens capitães assumiram as teses do General Spínola em seu livro. Esta avaliação, por sua vez, é bastante parcializada e merece análise mais aprofundada. ${ }^{11}$

Em 16 de março, cinco semanas antes da vitória do MFA, houve uma fracassada tentativa de derrubar o governo português. Uma coluna partiu de Caldas da Rainha (possivelmente um regimento leal a Spínola), mas sem encontrar apoio acabou retornando ao quartel e muitos rebeldes militares foram presos. Para $\mathrm{ZH}$, este movimento surgiu após “decisão tomada pelo primeiro ministro de destituir seus dois mais altos assessores militares" (17/3/74, p. 15). No mesmo dia, na edição do CP destaca-se que foi "Dominada rebelião militar em Portugal - tratou-se de um pequeno problema e a situação totalmente sob controle" (17/3/74, capa).

Este "pequeno problema" resultou em 33 presos na versão do governo ou mais de 300 presos na versão do MFA. ZH, ao mesmo tempo em que considerou este episódio a maior crise nos últimos 40 anos lusitanos, preocupou-se em apresentar entrevista do Ministro das Relações Exteriores português em visita ao Brasil, sr. Rui Patrício, que afirmou ser o motim militar "nada mais foi do que uma tranqüila passeata e um ato isolado sem nenhuma

${ }^{11}$ Para Secco, Spínola deu a legitimidade de um general para o MFA, composto de oficiais médios, o que exigiu por parte deste movimento aceitar uma série de condicionantes para tê-lo como aliado (2004, p. 111). 
conseqüência". Na mesma entrevista Rui Patrício reafirmou a manutenção da política portuguesa na África, como havia feito seu superior Marcelo Caetano no dia anterior (19/3/74, p. 12).

$\mathrm{Na}$ seqüência, o jornal CP optou por destacar o conteúdo de nota pública do MFA onde estes criticam "a cegueira administrativa, a prisão de oficiais e afirma ter aprendido as lições dos últimos acontecimentos e que vão seguir sua ação” (27/3/74, p. 2). CP dá amplo espaço da visão do MFA, algo não encontrado em ZH no mês de março de 1974. Durante a Revolução, os periódicos também tiveram distintas abordagens.

\section{O 25 de abril português em $\mathrm{ZH}$ e $\mathrm{CP}$}

\section{ZH e o golpe militar}

Toda a crise portuguesa e a ação de 25 de abril foi, para ZH, tida como Golpe Militar, termo destacado na capa de 26 de abril. Lá, ZH concedeu espaço para a posição dos guerrilheiros angolanos perante a revolução que ocorria na metrópole. Destacou uma entrevista de Agostinho Neto, líder do MPLA, para quem "o golpe pode relaxar o controle das colônias, mas julga que Portugal continuará tentando explorar as terras africanas através de meios menos repressivos" (26/4/74, p. 12).

Os africanos tinham razão de sobra para desconfiança, pois Spínola, o militar autorizado pelo MFA para assumir o poder no país em 25 de abril, tinha deixado claro em sua obra "Portugal e o Futuro" sua visão sobre a independência das colônias.

Durante a semana da Revolução, ZH ainda fez todo um histórico da situação portuguesa e ainda usou artigo de enviado internacional, François Pelou e seus contatos com militares rebeldes: "Consegui falar com um tenente, que a princípio relutou em falar. Acabou dizendo: 'Desta vez tudo saiu bem. Não houve contradições nas ordens'. Falava da frustrada revolta de Caldas da Rainha” (26/4/74, p. 13).

O mesmo François, destacou em longo artigo o papel de libertador da pátria de Spínola, aclamado como herói na derrubada do velho regime. Ao mesmo tempo, considerou que "O aparecimento de bandeiras vermelhas e distintivos de foice e martelo demonstraram uma inexperiência política compreensível, mas que pode custar o próprio preço da reabertura democrática".

ZH, ao repassar o conteúdo dos artigos da AFP de François, colocou em destaque a aposta no moderamento da revolução e sua rejeição à presença e aos objetivos das bandeiras vermelhas. Ao mesmo tempo, ocorreu um silenciamento na cobertura de $\mathrm{ZH}$ em relação ao 
MFA. Mentor intelectual da ação, praticamente não é citado em toda narração do ocorrido. Este fato lembra a análise de Ingo Voese: "é preciso revelar o não-dito, isto é, os silenciamentos e as contradições de ordem ideológica” (2002, p. 194).

Em destacado artigo, Newton Carlos profetizou que o "grande dilema português, a questão colonial, ainda está longe de encontrar um desfecho seguro e pacífico" (ZH, 26/4/74, centrais). Dias depois, Olyr Zavaschi, afirmou

\begin{abstract}
é muito improvável que um militar como Spínola - criado dentro do corporativismo salazarista ao qual serviu com risco de vida, ex-voluntário das legiões franquistas na Guerra Civil Espanhola, admirador do III Reich - se converta num líder de transformações políticas corajosas. É improvável também que as bandeiras vermelhas, que começaram a ser carregadas por braços jovens pelas ruas de Lisboa, tenham uma trajetória mais do que fugaz (ZH: 28/4/74, p. 18).
\end{abstract}

As previsões de Newton Carlos e de Zavaschi se colocaram como corretas, mas para chegar a elas, o contexto português de 25 de abril até o final de 1975 foi altamente explosivo. Quanto às bandeiras vermelhas, estas contribuíram para profundas transformações na economia e na sociedade portuguesa.

As primeiras medidas da junta governativa tiveram destaque nas edições de $\mathrm{ZH}$ em abril, bem como das propostas do governo provisório, em especial a liberdade de imprensa, de organização, reunião e de expressão, as eleições para assembléia constituinte, bem como a plena substituição e todos os funcionários salazaristas, muitos presos nas antigas prisões políticas do regime deposto.

A Junta também anunciou a pretensão de logo ceder o poder a um governo civil de coalizão provisório com várias tendências políticas. A questão africana apareceu inicialmente bastante secundária. "Interrogado se abriria diálogo com os movimentos guerrilheiros de libertação, o general Spínola respondeu que 'ainda não'”.

\title{
CP e a importância do MFA
}

O jornal CP considerou a ação de 25 de abril como uma Rebelião Militar e utilizou como fontes basicamente os discursos orais dos rebeldes a partir do conteúdo das transmissões da Emissora Nacional, ocupada pelos revoltosos: comunicado anunciando a rendição de Caetano era assinado pelo 'Movimento das Forças Armadas'. Segundo as informações disponíveis, os rebeldes controlavam a maior parte do país” (26/4/74, capa).

Utilizando as fontes revolucionárias, CP logo destacou os objetivos da ação: assembléia constituinte, restauração dos direitos dos cidadãos, paz na África e respeito aos 
compromissos no exterior. Além disso, deu grande amplitude à participação do MFA (ao contrário de $\mathrm{ZH}$ ) no processo de derrubada de Caetano e aos jornais portugueses de 26 de abril, que saíram sem censura. Após a vitória da ação, o MFA divulgou nota totalmente reproduzida por CP como 'A Proclamação do Movimento'. Mesmo longa, merece a descrição de parte dela:

Considerando que ao fim de 13 anos de luta em terras de ultramar, o sistema político
vigente não conseguiu definir concreta e objetivamente, uma política ultramarina que
conduza a paz entre os portugueses de todas as raças e credos; (...) o Movimento das
Forças Armadas que acaba de cumprir, com exxito, a mais importante das missões
cívicas dos últimos anos da nossa História, proclama à Nação a sua intenção de levar
a cabo até sua completa realização, um Programa de Salvação do País, de restituição
ao povo português das liberdades cívicas de que vem sendo privado. Para o efeito
entrega o governo a uma Junta de Salvação Nacional, a quem exige o compromisso,
de acordo com as linhas gerais do Programa do Movimento das Forças Armadas, (...)
o Movimento das Forças Armadas apela para calma e civismo de todos os
portugueses e espera do país a adesão dos poderes instituídos em seu benefício.
Saberemos, deste modo honrar o passado com respeito pelos compromissos
assumidos perante o país e, por este, perante a terceiros. Ficamos na plena
consciência de haver cumprido o dever sagrado de restituição à Nação dos seus
legítimos e legais $(26 / 4 / 74$, p. 3).

Cabe lembrar que o tal Programa do $M F A$ foi costurado entre os capitães e o próprio Spínola. Este fato é destacado por Secco como demonstrativo das divergências entre Spínola e os capitães: Spínola impôs retirar expressões como "projeto político, juventude fascista, controle imediato da emissora nacional e da radio e TV portuguesa, ordem democrática e colocava 'a discutir' a permissão de livre associação política” (2004, p. 111).

Para o CP, o primeiro ministro Marcelo Caetano era considerado "membro da direita dominante" e foi um governo de crises, especialmente por continuar a guerra na África, sem compromissos com as colônias nem com os gastos do país nos combates $(26 / 4 / 74$, p. 2).

O fim da velha ordem lusitana foi narrado em detalhes desde o refúgio no Palácio do Carmo até a rendição do governo e da Guarda Nacional. Outros detalhes como a desobediência das tropas oficiais e a fuga de ministros por túneis coloriram o final dramático do antigo sistema português. Impossível para CP foi ignorar a festa popular ocorrida nas ruas de Lisboa, "semelhante às festas de libertação ao finalizar a Segunda Guerra Mundial na Europa Ocidental” (26/4/74, p. 3).

O CP também abriu espaço para os líderes africanos. Desde sua manchete, ficou claro que "Líder angolano diz que só a independência dará fim à luta" (26/4/74, p. 3). numa referência às posições de Agostinho Neto. O próprio jornal, em editorial do dia 27 de abril, diz não acreditar na "Confederação Africana” proposta por Spínola. 
Sobre Spínola, aliás, o CP divulgou claramente sua posição, enquanto presidente provisório, contra as independências africanas. Para ele, se "ou o povo africano aceitará permanecer dentro da comunidade portuguesa (...) ou se pronunciará a favor da independência, o que significará nosso fracasso" (30/4/74, capa).

Claramente, o êxito para Spínola seria a manutenção das relações coloniais sobre novas bases. Esta posição acabou entrando em choque com a esquerda agora legalizada ${ }^{12} \mathrm{em}$ Portugal e com boa parte do MFA. Cabe destacar, por outro lado, que fruto de uma crise política constante e de atritos entre várias concepções políticas, os portugueses tiveram seis governos provisórios entre maio de 1974 e setembro de 1975, num ciclo de crises políticas e rearranjos.

O convulsionado Portugal seguiu sendo atormentado pelas lutas metropolitanas como reflexo, em boa parte, das lutas coloniais que seguiram em 1974 e 1975, pois a partir da Revolução de Abril foi criada grande expectativa para a solução da guerra colonial.

Houve certa frustração nos primeiros momentos por não ocorrer uma solução automática do colonialismo, pois Spínola resistiu ao reconhecimento automático da independência em vários encontros de negociação, em discursos e entrevistas registradas pela imprensa. Foram necessários novos acontecimentos para que a libertação africana fosse consolidada.

Para Netto, o fim do fascismo português ${ }^{13}$ acabou coroado com a descolonização, "cujo mérito maior cabe aos movimentos de libertação articulados pelos povos submetidos ao jogo colonial - mas, sem o 25 de abril, seguramente ainda se prolongaria por mais tempo à política de terra arrasada dos colonialistas" (1986, p. 56).

$\mathrm{O}$ autor ainda identifica três posições distintas a cerca da guerra colonial: primeira, a defesa de uma Federação Lusitana com sede em Lisboa, segunda, a independência mantendo vínculos econômicos privilegiados e a terceira, o reconhecimento pleno das independências e acordos com os movimentos de libertação. As diversas facções políticas da Revolução acabaram optando por alguma destas propostas. Spínola assumiu a primeira.

\footnotetext{
12 Com a anunciada liberdade de organização, vários partidos foram legalizados. Os dois mais destacados no contexto pós-revolucionário foram o Partido Socialista de Mário Soares e o Partido Comunista de Álvaro Cunhal (Ver MAXWELL, 2006).

${ }^{13}$ Complementando a visão de Netto, Secco afirma que “(...) não se pode ignorar que o colonialismo português era um sistema, uma unidade na diversidade, em que as partes não poderiam sobreviver da mesma forma sem as conexões internas recíprocas. A superação do sistema, por isso, também não poderia se dar apenas a partir de dentro. Era preciso uma nova conjuntura internacional que forçasse a rebeldia interna e a modificação das formas de pensamento (...)" (2004, p. 88).
} 
O Programa do Movimento das Forças Armadas, mentor intelectual e prático da Revolução, é considerado por Silva dúbio e frágil no tocante à guerra colonial, pois visava tão somente "a obtenção da paz, quer dizer, o abandono da solução militar e não, imediata ou necessariamente, a descolonização nem, muito menos, a independência das colônias portuguesas" (1997, p. 161).

Ligado à visão africana, Silva chega a considerar que as verdadeiras revoluções foram feitas nas colônias. Coincide com a opinião de Maria Linhares, para quem "o povo português era o primeiro a ser libertado em grande parte graças à luta heróica dos guerrilheiros africanos" (1997, p. 104).

O abandono da solução militar como item programático do MFA era o discurso spinolista dominante naquele momento. Era um abandono militar relativo, pois para concretizar uma Federação Lusitana, seria necessário construir acordos a partir de vantagens militares pela via da guerra. Esse aspecto é mais um exemplo de concessão programática dos capitães à visão de Spínola para o fechamento da Revolução nas vésperas de 25 de abril. É bem analisado por Ki-Zerbo para quem Spínola "que durante algum tempo encarnara o processo para melhor o canalizar e depois o refrear, tentou limitar os estragos por meio de uma autonomia concedida" (2002, p.280).

Independente da vontade de Spínola, diversos fatores levaram a ruptura colonial. Silva destaca a situação interna e as freqüentes contradições e mudanças no próprio aparelho de Estado, a pressão da comunidade internacional por uma solução e as posições dos movimentos de libertação, intransigentes quanto à necessidade de transferir poderes rumo à independência.

A debilidade do governo português combinado com a pressão dos movimentos nacionalistas e uma seqüência de fatores e conflitos levaram à consolidação de normas para a descolonização. Os portugueses negociaram separadamente caso a caso a independência de suas colônias sentando à mesa com os grupos guerrilheiros de libertação nacional, que para Hobsbawm "foram os agentes principais para a emancipação política da maior parte do planeta" (2004, p. 196).

\section{Os caminhos da independência de Angola em ZH e CP}

A partir da posse da Junta de Governo após a derrubada de Caetano, o tema da descolonização jamais deixou a pauta política. Já nos acertos para a formação do primeiro governo provisório se delineavam as posições em debate. Mário Soares, líder do PS retornado do exílio, chegou a temer que o conflito africano "se tornasse um novo Vietnã para Portugal" 
(CP,1/5/74, p. 2). Soares, Cunhal pelo PC e outros representaram a esquerda no Governo Provisório português nascido da Revolução dos Cravos. ${ }^{14}$

Toda esta trama foi ricamente descrita em ZH e CP, onde houve espaço para governantes, guerrilheiros e comentaristas da realidade. Agostinho Neto, bastante destacado na imprensa no Rio Grande do Sul, sempre deixou claro que os angolanos precisavam continuar sua luta contra os portugueses: “A independência logo estará entre nós, porém não há caminhos pelos quais eu possa entrar em Lisboa para negociações. Somos classificados de terroristas ou algo pior que idealistas" (CP, 1/5/74, p. 2). Ao mesmo tempo, Spínola insistia que "os africanos não estavam preparados para sua autodeterminação" (ZH, 1/5/74, p. 14).

Dias após, uma clara exigência da Junta é destacado em CP. Impunha-se a deposição de armas pelos guerrilheiros para ocorrer negociações, (4/5/74, capa) justamente numa conjuntura militar desfavorável aos portugueses. Soares respaldou esta política em entrevista coletiva realizada na cidade de Londres. ${ }^{15}$

Apesar da política da Junta, os atritos continuaram. Com bastante clareza, em comunicado da Junta foi afirmado que o governo "não admite que autoridade dos novos governantes seja posta em dúvida" e que "Portugal manterá a guerra em suas províncias africanas até que se encontre uma solução política para terminá-la” (CP, 5/5/74, capa).

Newton Carlos, em esclarecedor artigo, relacionou a permanência de Portugal na África com os interesses de investimentos estrangeiros no Petróleo, algodão, estradas de ferro, café, entre outros diretamente nas colônias. Tratava-se da pedra fundamental para se entender a resistência de setores do novo regime português. "Esses interesses tem procurado ajudar na permanência do poder político português, como garantia de sua própria permanência”, conclui o analista (ZH: 5/5/74, p. 18).

Neste contexto, restou a Agostinho Neto como líder angolano comentar que até aquele momento "Spínola não disse nada de aceitável para nós” (CP: 7/5/74, capa).

\footnotetext{
14 Conforme análise de Secco (2004), o Partido Socialista de Soares, que acabou se tornando hegemônico nas eleições portuguesas, tinha referência política nos moderados sistemas da social democracia européia. O Partido Comunista de Álvaro Cunhal não seguia as orientações mais pacifistas de seus co-irmãos europeus. Foi adepto de teses insurrecionais para derrubar o fascismo, mas moderou-se após o 25 de abril. Chegou a condenar as greves e movimentos populares em defesa do governo e aceitou Portugal como membro da OTAN ao mesmo tempo em que retirou o famoso termo 'ditadura do proletariado' de seu programa. O PS e o PC tiveram fortes contradições entre eles dentro do processo revolucionário português. Compuseram a maior parte dos governos provisórios e defenderam a independência das colônias de forma mais acelerada que outros setores do governo. Tanto o PS como o PC sofreram fortes críticas de diversas tendências da esquerda (trotsquistas, maoístas e anarquistas) que os acusavam de 'representantes ou parceiros da burguesia e do capitalismo dentro da revolução'.

15 "Necessitamos de um cessar-fogo tão logo seja possível e, em seguida, iniciar negociações com os movimento de libertação nacionalistas para que a independência seja conseguida no mais breve prazo" (ZH: 3/5/74, p. 14).
} 
Para ZH, a lua de mel entre a Revolução portuguesa e as colônias já estava abalada nesta altura (8/5/74, p.13) e ZH insistiu em confirmar a intenção de parte da Junta em continuar a guerra colonial, mas com a posse do I Governo Provisório, as coisas mudaram.

Spínola continuou sendo o chefe de governo, agora oficialmente como presidente. Constituiu um governo de coalizão, que segundo ZH incluiu "6 esquerdistas" (17/5/74, p. 11), quatro do PS e dois do PC, tendo a cabeça o primeiro ministro Adelino da Palma Carlos. Na mesma reportagem, ZH destacou que o novo governo manteria "operações defensivas nas colônias africanas em busca de uma solução política”. Esta solução política acabou sendo, apesar da resistência de vários setores, os acertos para as independências coloniais.

A independência de Angola, a mais rica colônia portuguesa, foi a mais difícil e dramática. Angola era estratégica do ponto de vista geopolítico e econômico para as potências da Guerra Fria de um lado e para as grandes empresas transnacionais e seus investimentos de outro.

A luta em Angola iniciou nos anos 1960, especialmente com a independência do Congo: "era um contexto continental de descolonização, uma fronteira comum com um país independente amigável, uma unidade étnica do dois lados da fronteira, eram as precondições cruciais de uma insurreição destinada ao êxito” (ANDERSON: 1966, p. 101).

O conflito em Angola sempre teve a marca da violência extremada. Durante a guerra contra os portugueses, até os anos 1970, foram montados três exércitos: o MPLA que convergia a esquerda com referência no modelo soviético, a FNLA patrocinada por chineses e estadunidenses e ainda a UNITA, com inserção entre os brancos que também recebeu apoio militar e financeiro de países centrais capitalistas e ainda da África do Sul.

Os movimentos nacionalistas angolanos jamais controlaram o centro e o sul do país, mas cresceram politicamente junto com a onda da descolonização africana e foram por isso gabaritados para representar o povo angolano nas negociações com Portugal após 25 de abril.

A imprensa no Rio Grande do Sul deu grande destaque a este fator: já em maio de 1974, um mês após a Revolução metropolitana, Portugal decretou "cessar fogo em Angola para início de conversações. Ordem para 70 mil soldados não agirem contra a guerrilha" (CP: 21/5/74, capa).

Esta medida não evitou a marca fundamental da relação entre os grupos guerrilheiros, Portugal e a independência: divisão entre os grupos guerrilheiros, inúmeros acordos e tratados assinados descumpridos e as marcas de barbárie no conflito entre os próprios angolanos. 
No mês de maio já foram registrados os primeiros conflitos entre brancos e negros e em julho ocorreram 30 mortes em lutas contra policiais. O toque de recolher, imposição tradicional no meio das crises e das lutas armadas neste período, constantemente foi utilizado.

A constante violência obrigou Portugal a impor uma Junta Militar pra governar a colônia que tomou posse em setembro e ainda divulgar a primeira proposta para independência da colônia: “(...) trégua, governo provisório amplo e lei eleitoral que dê a um homem, um voto. Em dois anos, Assembléia Constituinte elabora lei e dissolve-se, depois é eleito governo livre e soberano" (CP: 11/8/74, capa).

ZH já alertava para o risco de guerra civil em Angola: "o clima de tensão e o perigo de uma guerra sangrenta entre 600 mil brancos, os guerrilheiros e os grupos tribais não deixaram de crescer nos últimos dias" (11/8/74, p. 13). O jornal destacou as diferenças tribais e étnicas entre vários grupos que teriam, na proposta de Portugal, participação no Governo Transitório até a independência.

Os impasses continuaram, comícios e movimentos políticos pela independência se alastraram por Angola, inclusive com repressão por parte da polícia portuguesa. Em setembro, ocorreu a posse de Governo Provisório amplo, idealizado pelos portugueses:

A Junta presidida pelo Almirante Coutinho, de Angola, anunciou ontem a constituição de um governo provisório, composto por personalidades de diversas tendências, embora o MPLA exerça nele a maior influência. Este gabinete provisório terá duração muito limitada, pois deverá ser substituído por um verdadeiro governo angolano (ZH: 6/9/74, p. 14).

Em seguida, os portugueses anunciaram o desejo de seguir as negociações em uma frente comum, que incluísse os vários grupos guerrilheiros (CP: 12/9/74, capa.). Com a queda de Spínola e a chegada de Costa Gomes a presidência, o Primeiro ministro Vasco Gonçalves deu este norte para os caminhos da independência.

Em novembro de 74, CP destacou a retomada das violências em Angola que levaram a dezenas de mortes. Mercenários eram contratados para atuar nos conflitos e havia a certeza neste periódico que sem um acordo entre os grupos, a guerra civil seria inevitável.

Em dezembro, o jornal anunciou a "intenção portuguesa da independência angolana para 1975. Este mês, reunirão os três movimentos de libertação para formar governo com ministros de todos os grupos” (4/12/74, capa). Este anúncio revogou a idéia anterior que dava o prazo de dois anos para independência completa. As decisões foram jogadas para o ano de 1975, ano intenso para a vida do povo angolano, pois ali se decidiu o futuro da rica colônia. 
No início de 1975 foi assinado o histórico Acordo de Alvor (cidade portuguesa) entre portugueses e os três grupos angolanos. Dias antes, em Mombasa (Quênia), MPLA, FNLA e UNITA construíram consensos em torno a uma ação comum ante os portugueses e havia um clima de otimismo (4/1/75, p. 2), mas havia desconfiança ante o anúncio dos acordos políticos e sobre a consolidação da paz e sua real aplicação. Entre 9 e 15 de janeiro, estes acordos foram assinados. ${ }^{16}$

Ao analisar este acordo, Ki-Zerbo o ponto de partida para o caos: "Todos os movimentos se armaram junto de fornecedores. (...) aos dois principais protagonistas repugnava levar a cabo de imediato as eleições previstas" (2002, p. 283). Os protagonistas eram MPLA e FNLA e os aspectos centrais do Acordo, ninguém cumpriu.

A posse deste governo tripartido ocorreu no início de fevereiro. Logo em março novos choques ocorreram em Angola. Neste primeiro momento o motivo principal foi o enclave de Cabinda, ao norte, onde o MPLA interviu contra intenções separatistas. Depois, veio o enfrentamento nas ruas: "Em Angola, 66 pessoas morreram em uma semana. Com o toque de recolher, a situação se estabilizou. Luanda é controlada por tropas mistas" (CP, $30 / 3 / 75$, p. 3).

$\mathrm{ZH}$ voltou a tocar em Angola apenas em maio, quando MPLA e FNLA "lutaram ontem com granadas de mão e fogo de morteiros (...) pelo menos 250 pessoas morreram e outras ficaram feridas" (3/5/75, p. 11). Eram os indícios do que ocorreu nos meses seguintes. O número de mortos chegou ao redor de 500 ao final das contas neste conflito de cinco dias em maio.

A partir deste episódio foram registrados conflitos raciais, fugas dos portugueses, expulsão de estrangeiros responsabilizados pelos conflitos, falta de comida e gêneros básicos. Segundo CP, chegou a 3 mil o número de mortos e os portugueses retomaram a responsabilidade sobre o território, visto que "guerrilheiros violaram clausulas do acordo assinado em Lisboa" (16/5/75, capa).

Em junho, novos conflitos: a empresa exploradora de petróleo em Cabinda se retira, em Luanda e até hospitais foram vitimados por tiros que mataram pacientes. CP indicava nova reunião entre os grupos guerrilheiros (7/6/75, capa), ao mesmo tempo em que $\mathrm{ZH}$ dava

16 Os principais pontos deste acordo determinaram: “o 11 de novembro próximo para a declaração de independência (...) o acordo estabelece que os movimentos guerrilheiros farão parte de um Conselho Presidencial, constituído por três pessoas, o qual governará a colônia, até que seja escolhido - em eleições livres o presidente que deverá dirigir o país e os membros da Assembléia Legislativa. Uma Assembléia Constituinte será eleita para dar ao país sua constituição. Nesse período de transição, cada um dos três grupos terá o direito de nomear um número igual de ministros" (ZH: 16/1/75, p. 11). 
espaço para o discurso dos líderes da FNLA, algo costumeiro a partir de então. Neste momento, A FNLA denunciava a ajuda soviética e chinesa aos combatentes angolanos.

Portugal também agiu militarmente antes da independência: pára-quedistas ocuparam as sedes dos grupos guerrilheiros e pela primeira vez a data da independência foi ameaçada. A UNITA ameaçou entrar no conflito definitivamente a partir de um massacre realizado contra jovens militantes seus.

ZH narrou com detalhes a bárbara ação. Este jornal a partir de então será especialista em detalhar atrocidades ocorridas na guerra civil, destacando a barbárie: "Dezenas de jovens da UNITA foram degolados a faca onde as cabeças, separadas dos troncos a machadadas. O cheiro penetrante dos cadáveres e decomposição invade as ruas dos bairros pobres” (12/6/75, p. 17).

Enquanto isso, CP destacou os preparativos da reunião no Quênia, onde foi tentado novo acordo entre os grupos em guerra. Neste encontro, foi definido: "desarmamento da população civil, formação do Exército Nacional (máximo de 30 mil homens) e término da violência e da intimidação. Liberdade para atividades políticas no país e tolerância política com unidade nacional dentro da diversidade" (22/6/75, p. 3).

Mais uma vez, as intenções ficaram no papel. Em julho, os embates fizeram centenas de mortos mais uma vez (já passava de 2 mil as vítimas dos choques desde janeiro de 1975, segundo $\mathrm{ZH}$ ). "A violência armada eclodiu de novo violando a trégua que assinaram no mês passado em Quênia, deixando um saldo de 200 mortos em dois dias de luta” (12/7/75, p.12).

Os jornais gaúchos reconheceram a Guerra Civil em Angola a partir de 15 de julho, ${ }^{17}$ com a fuga dos quadros da FNLA para o norte do país, onde construiu sua resistência ao MPLA que dominou Luanda até a independência de novembro. Os portugueses, como um paradoxo, apenas seguiam uma "neutralidade ativa entre os dois grupos rivais. O objetivo dos portugueses é proteger cerca de 250 mil portugueses" (CP: 17/7/75, capa).

A partir da saída de FNLA pra o norte, ZH criou expectativa que estas tropas retornassem a Luanda, desbancando o MPLA. A torcida, como desejo subliminar, era clara nas matérias. Já no dia seguinte, a manchete era "FNLA reage e marcha sobre Luanda". (16/7/75, p. 12.). Esta reação do FNLA jamais se concretizou e $\mathrm{ZH}$ insistiu em divulgar uma vitória iminente deste grupo contra o "esquerdista MPLA" para seus leitores nos dias seguintes. ${ }^{18}$

\footnotetext{
${ }^{17}$ Segundo AREIA (2008, p. 77), “(...) a intensidade do recrutamento de soldados pelos três movimentos, por um lado, e por outro, os freqüentes confrontos, sobretudo em Luanda, entre militantes da UNITA e do MPLA, indiciavam claramente o clima de guerra civil que se adensava cada dia".

18 Apenas as manchetes de ZH confirmam esta afirmação: "Frente prepara-se para invadir Luanda" (21/7/75, p. 13), "Violentos combates a $50 \mathrm{Km}$ de Luanda" (23/7/75, p. 13), "Holden Roberto pede guerra total em Angola"
} 
Cabe salientar que CP também divulgou os movimentos da FNLA, mas de forma mais comedida.

Em 22/7/75 foi anunciada nova trégua e novo cessar fogo acabou assinado por MPLA e FNLA. Apenas simbólico, pois o avanço da FNLA se registrou já nos dias seguintes. "A luta entre MPLA e FNLA parecida adquirir hoje proporções de uma verdadeira guerra" (CP: 31/7/75, capa).

Em agosto, a UNITA entrou na guerra e acabou agindo em unidade de ação com a FNLA. ZH neste mês anunciou o controle de Luanda pelo MPLA, visto que os dois outros grupos se retiraram do governo provisório e tiraram suas tropas da capital. Ante esta situação, os portugueses retomaram o controle de Angola pela inexistência do governo tríplice, sem questionar a data prevista para a independência.

Enquanto a fome aumentava e áreas importantes da economia paralisavam por falta de braços qualificados (30 mil fugiam de Angola por mês), o MPLA avançou ocupando regiões importantes e controlou 12 das 16 províncias angolanas nas portas da independência.

Ao mesmo tempo, Portugal (em profunda crise e dividida entre facções militares e civis) anunciou a retirada de suas tropas até novembro, jogando para a ONU a responsabilidade sobre Angola. Em outubro, a OUA anunciou missão de investigação para pôr fim a guerra civil. Recebeu a simpatia das facções guerrilheiras, nada mais do que isso.

O quadro já estava praticamente delineado para o 11 de novembro, conforme o jornal CP: "O MPLA reivindicará para si o controle da nação no dia da proclamação da independência. (...) baseia sua reivindicação no fato de suas forças ocuparem a capital e o mecanismo administrativo do país" (17/10/75, p. 3).

Neste período, às vésperas de importantes batalhas antes do 11 de novembro, o MPLA recebeu o apoio internacionalista de centenas de cubanos, que chegaram em Angola para auxílio técnico e militar. ZH divulgou tal fato a partir de uma crítica de Jonas Savimbi, da UNITA, sem citar que a UNITA recebeu apoio de outras nações simpáticas às suas posições ideológicas. CP, não deu importância significativa ao apoio cubano neste momento.

Chaliand, refletindo Angola e suas dificuldades no início dos anos 80 relata: "O resultado final das diversas intervenções foi a presença de vinte mil cubanos (...) que constituem hoje a garantia mais segura do regime (...) considerando-se o vazio deixado pela partida de 300 mil colonos portugueses" (1982, p. 85).

(26/7/75, p. 12), "Batalha pela posse de Luanda aproxima-se" (27/7/75, p. 19), "FNLA aperta cerco sobre Luanda" (28/7/75, p. 14), "Frente Nacional fecha o cerco sobre Luanda" (31/7/75, p. 14). O conteúdo das reportagens, pelo menos na forma subliminar, colocava a FNLA como portadora do ideal democrático e o MPLA como mal a ser combatido. 
Apesar de todo quadro caótico, a hora da independência chegou. Os portugueses anunciaram no início de novembro detalhes de sua retirada e a entrega do país aos movimentos guerrilheiros, bem como do material militar "às autoridades colocadas em cada local (...). Também deixamos armas e material em zonas controladas pela FNLA e pela UNITA" (ZH: 2/11/75, p. 16). Neste contexto, a posse de Luanda foi fundamental para a transição de poder dos portugueses para o MPLA e não aos outros movimentos.

O MPLA ameaçou controlar Angola e declarar a independência de forma unilateral. Neto, publicamente denunciou a presença de mercenários e pediu ajuda militar às Nações Unidas: "O MPLA pediu hoje que os 550 mil habitantes de Luanda se preparem para o pesadelo: bombardeios que outros dois movimentos podem realizar nos próximos dias" (CP: $8 / 11 / 75$, capa).

A situação angolana retratada na imprensa pouco antes da independência era de intenso caos e, especialmente para $\mathrm{ZH}$, de forte melancolia e falta de perspectiva para o futuro:

\begin{abstract}
Alguns nostálgicos ainda vão cear perto de uma praia de areia fina que era cenário da dolce vida noturna durante o cálido verão angolano. Como vestígio dos anos dourados, perambulam perto dos restaurantes alguns negrinhos esfarrapados que assaltam os proprietários de carro, para, lavando-os, ganhar alguns escudos (9/11/75, p. 16).
\end{abstract}

Apesar destes curiosos relatos divulgados em ZH do "doce e dourado colonialismo" português ante o caos da guerra civil, Angola consolidou sua independência entre os dias 10 e 11 de novembro sob a hegemonia do MPLA. Para este grupo guerrilheiro, foi fundamental o apoio popular nos bairros, das armas soviéticas e dos soldados cubanos.

Estes elementos garantiriam a resistência do MPLA contra o FNLA especialmente na Batalha de Quifangondo, quando as tropas da FNLA foram barradas a poucos quilômetros de Luanda, 3 dias antes da independência, conforme relato de $\mathrm{ZH}$ : "milhares de soldados do MPLA, resistem com sucesso há algumas semanas ao ataque das tropas do FNLA, em Quifangondo, (...). As ofensivas lançadas pela FNLA em 23 de outubro passado (...) foram um fracasso" $(10 / 11 / 75$, p. 16).

Em 11 de novembro, como previsto, Agostinho Neto anunciou a República Popular de Angola, assumindo a presidência de um governo unipartidário. Os portugueses inicialmente não reconheceram o novo governo, algo feito por cerca de 30 países (inclusive o Brasil), naqueles primeiros dias. A transferência de poder por parte dos portugueses, não foi direta: 
Nenhum dos três movimentos nacionalistas foi convidado para a cerimônia de arriamento da bandeira portuguesa,(...), que marcou oficialmente o término dos 500 anos de dominação colonial em Angola. O Almirante Leonel Cardoso (...) recolheu a bandeira e imediatamente deixou o novo país. Designando o seu dirigente máximo o poeta Agostinho Neto (...) como primeiro presidente da República (CP: 11/11/75, capa).

ZH destacou, dentro de seu tradicional conteúdo, que "O futuro de Angola continua sendo sombrio e por agora parece que deve excluir-se toda a solução que não seja militar". Ao mesmo tempo colocou a ameaça de separatismo no horizonte político angolano ao noticiar o anúncio paralelo de independência realizado por FNLA e UNITA (11/11/75, p. 14). CP, por sua vez, considerou Angola "outrora próspera colônia do Império Português e agora terra devastada que se debate na agonia da guerra civil" (11/11/75, p. 3).

Em seu discurso de posse, Agostinho Neto afirmou que

“Angola

vai se converter, progressivamente, em uma democracia popular, ao mesmo tempo em que reiterava sua vontade de continuar a luta até a libertação total de seu país" (ZH: 12/11/75, p. 12). No mesmo dia, Neto escapou de atentado e Luanda continuou ameaçada por tropas do FNLA e UNITA.

Nos dias seguintes da independência, Luanda foi defendida pelas tropas do MPLA, por cubanos, moçambicanos e apoiadores de Neto. Assim, vários ataques foram repelidos contra sul africanos, ex-soldados portugueses e toda sorte de mercenários.

Em Cabinda, o MPLA também resistiu contra as forças o Zaire, opositoras a Neto. No CP, foi divulgada denúncia da UNITA sobre "agitadores esquerdistas brasileiros estão colaborando intensamente com o governo de Agostinho Neto, que ocupa ilegalmente o governo do país" (26/11/75, p. 3). Numa guerra aberta e internacional no território angolano, cada lado acusava os aliados de seus inimigos.

O apoio diplomático de alguns países, gradualmente conquistado por Neto, e o reforço do bloco socialista da Guerra Fria deram ao governo de Neto vitórias importantes ao norte e ao sul. Receando novo Vietnã, com feridas bem abertas em 1975, os EUA se retiraram do processo em dezembro com a negativa do Senado americano em autorizar tropas ou dinheiro para qualquer grupo em Angola. Assim, UNITA e FNLA não puderam contar oficialmente com recursos deste importante aliado.

Neto e o MPLA foram consolidando a sua República Popular unipartidária nos meses seguintes à independência, ficando clara a influência da Guerra-Fria nesta verdadeira guerra internacional africana. Para a URSS e Cuba era fundamental a existência de nações influenciadas pelo bloco socialista nesta região da África. 
Outros fatores foram destacados por Newton Carlos em sua coluna de ZH: "A luta em Angola, com intervenções da URSS, EUA, China e países europeus, (...) que participa da exploração de petróleo de Cabinda, se encaixa no futuro global de uma região conhecida como pepita austral do continente africano" (12/11/75, p. 12).

A peculiaridade da luta pela independência angolana, num quadro de intensa intervenção das potências, ${ }^{19}$ tornou um dos países mais ricos da África (em potencial) em um dos mais pobres do planeta. A Guerra Civil continuou vários anos após 1975, ${ }^{20}$ o que tornou Angola sinônimo de destruição, barbárie, minas explosivas e banhos de sangue no imaginário de boa parte da humanidade até recentemente.

\section{BIBLIOGRAFIA E FONTES CONSULTADAS}

\section{Obras gerais.}

1. ALEnCASTRE, Amilcar. América Latina, África e Atlântico Sul. Rio de Janeiro: Editora Paralelo, 1980.

2. ALVES, Maria H. Moreira. Estado e Oposição no Brasil (1964-1984). São Paulo: Vozes, 2004.

3. ANDERSON, Perry. Portugal e o fim do Ultracolonialismo. Rio de Janeiro: Editora Civilização Brasileira, 1966.

4. AQUINO, Maria Aparecida de. Censura, Imprensa Estado Autoritário (19681978). São Paulo: EDUSC, 1999.

5. BRUnSCHWIG, Henri. A Partilha da África Negra. São Paulo: Perspectiva, 2004.

6. CHALIAND, Gerard. A Luta pela África. São Paulo: Brasiliense, 1982.

7. COMITINI, Carlos. África Arde. Rio de Janeiro: Editora Codecri, 1980.

8. DOLGOPOLOV, E. As Guerras de Libertação na Etapa Actual. Moscou: Editora Progesso, 1986.

9. FERRO, Marc. História das Colonizações. São Paulo: Cia das Letras, 1996.

\footnotetext{
${ }^{19} \mathrm{CP}$ destacou manchetes importantes que retrataram as intenções intervencionistas das potências. Duas capas em dezembro de 1975 se definem pelo conteúdo: "Kissinger ameaça com intervenção em Angola" (13/12/75, capa) e "Soviéticos defendem a intervenção em Angola" (27/12/75, capa).

${ }^{20} \mathrm{O}$ conflito entre MPLA e UNITA (FNLA se enfraqueceu nos anos 80) se estendeu até o fim da Guerra Fria. Em 1989 acordos de paz foram assinados e logo descumpridos, seguindo a velha regra. Após o fim da URSS, em 1991, foram assinados acordos de Bicesse que encerrou a guerra civil convocando eleições para 1992, vencidas pelo MPLA. Novo conflito após o resultado eleitoral e novo acordo em 1994, em Lusaca. Apenas em 2002, a UNITA, a partir da morte de Jonas Savimbi, renunciou a luta armada e tornou-se partido político em Angola.
} 
10. FILHO, Ciro Marcondes. Imprensa e Capitalismo. São Paulo: Editora Kairós, 1984.

11. HERNANDEZ, Leila L. A África na sala de aula. São Paulo: Selo Negro, 2005.

12. HOBSBAWM, Eric. A Era dos Extremos. São Paulo: Cia das Letras, 2003.

13. Nações e Nacionalismo desde 1780. São Paulo: Paz e Terra, 2004.

14. ILIFFE, John. Os africanos: História de um Continente. Lisboa: Editora Terra Mar, 1995.

15. KAPUSCINSKI, Ryzsard. Ébano: minha vida na África. São Paulo: Cia das Letras, 2002.

16. KI-ZERBO, Joseph. História da África Negra. V. II. Lisboa: Publicações EuropaAmérica, 2002.

17. LINHARES, Maria Yedda. A Luta contra a Metrópole. São Paulo: Brasiliense, 1983.

18. LOPEZ, Luiz Roberto. História do Século XX. POA: Mercado Aberto, 1987.

19. MAXWELL, Kenneth. O Império Derrotado. Revolução e Democracia em Portugal. São Paulo: Cia das Letras, 2006.

20. NETTTO, José Paulo. Portugal: do Fascismo à Revolução. POA: Mercado Aberto, 1986.

21. N`KRUMAH, Kwame. Neocolonialismo - último estágio do imperialismo. Rio de Janeiro: Civilização Brasileira, 1967.

22. PAULINO, Robério. Socialismo no século XX: O que deu errado? Goiânia: Editora Kelps, 2008.

23. READER, John. África: Biografia de um Continente. Lisboa: Publicações EuropaAmérica, 2002

24. SANTOS, Fernando B. Angola na Hora Dramática da Descolonização. Lisboa: Editora Prelo, 1975.

25. SECCO, Lincoln. A Revolução dos Cravos. São Paulo: Editora Alameda, 2004.

26. SILVA, Antônio E. Duarte. A Independência da Guiné-Bissau e a Descolonização Portuguesa. Porto: Editora Afrontamento, 1997.

27. VICHINSKI, Mikhail P. Sul da África: o Apartheid, o Colonialismo a Agressão. Moscou: Editora Progresso, 1987.

28. VISENTINI, Paulo G, Fagundes. A África Moderna: um continente em mudança (1960-2010). Porto Alegre, Editora Leitura XXI, 2010. 
29. A Guerra Fria o desafio socialista à ordem americana. Porto Alegre, Editora Leitura XXI, 2004.

\section{Artigos consultados.}

30. ABRAMO, Perseu. Significado político da manipulação na grande imprensa. IN: Fragmentos de Cultura. Goiânia: IFITEG, 1991.

31. AREIA, M. Laranjeira Rodrigues. A Diversidade cultural e a construção do EstadoNação em Angola. IN: Comunidades Imaginadas - Nações e Nacionalismos em África. Coimbra: Imprensa da Universidade, 2008.

32. BENITES, Sônia Aparecida Lopes: A História contada nas páginas de jornais. IN: Revista Letras. Curitiba, Editora da UFPR, 2001.

33. CATROGA, Fernando. Pátria, Nação, Nacionalismo. IN: Comunidades Imaginadas - Nações e Nacionalismos em África: Coimbra: Imprensa da Universidade, 2008.

34. GOMES, Nilo Sérgio. A imprensa carioca na virada do século $\mathbf{X X}$ - Memórias do JB, disponível em: < http://www.unirio.br/morpheusonline> acesso em 20/2/2006.

35. PIMENTA, Fernando Tavares. Nacionalismo Euro-africano em Angola - Uma nova Lusitânia? IN: Comunidades Imaginadas - Nações e Nacionalismos em África: Coimbra: Imprensa da Universidade, 2008.

36. RECH, Maria H. Bortolon; FELTES, Heloísa P. de Moraes. No Fio do Discurso: Análise do discurso sobre o Trabalho no Artigo Opinativo do Jornal Correio Riograndense. IN: Linguagem em Discurso. Tubarão: Editora UNISUL, 2005.

37. RODRIGUES, Maria Guadalupe M. As relações Estados Unidos - Angola: estudo do processo decisório na crise angolana. IN: Estudos Afro-Asiáticos, No 19, Dez. 1990, Rio de Janeiro: Editora Universidade Cândido Mendes, 1990.

38. SANTOS, Daniel dos. Sociedade política e formação social angolana (1975-1985) IN: Estudos Afro-Asiáticos. No 32, Dez. 1997, Rio de Janeiro: Editora Universidade Cândido Mendes, 1997.

39. VISENTINI, Paulo G, Fagundes. A África independente/1945-98: processos políticos, desenvolvimento e relações internacionais. IN: Ciências e Letras - Revista da FAPA. N 21/22, Nov. 1998, Porto Alegre: Edelbra, 1998.

40. VOESE, Ingo. Reflexões sobre a Análise do discurso. IN: Linguagem em discurso. Tubarão: Editora UNISUL, 2002.

\section{Acervos pesquisados.}

41. Museu de Comunicação Social Hipólito José da Costa (Porto Alegre/RS).

42. Arquivo privado do Jornal Zero Hora.

43. Arquivo privado do Jornal Correio do Povo. 
Artigo recebido em: 14/10/2011

Aprovado em: 03/12/2011 